\title{
Minimally Invasive Spinal Stabilization Using Fluoroscopic-Guided Percutaneous Screws as a Form of Palliative Surgery in Patients with Spinal Metastasis
}

\author{
Mun Keong Kwan, Chee Kean Lee, Chris Yin Wei Chan \\ Department of Orthopaedic Surgery, Faculty of Medicine, University of Malaya, Kuala Lumpur, Malaysia
}

\begin{abstract}
Study Design: Prospective cohort study.
Purpose: To report the outcome of 50 patients with spinal metastases treated with minimally invasive stabilization (MISt) using fluoroscopic guided percutaneous pedicle screws with/without minimally invasive decompression.

Overview of Literature: The advent of minimally invasive percutaneous pedicle screw stabilization system has revolutionized the treatment of spinal metastasis.

Methods: Between 2008 and 2013, 50 cases of spinal metastasis with pathological fracture(s) with/without neurology deficit were treated by MISt at our institution. The patients were assessed by Tomita score, pain score, operation time, blood loss, neurological recovery, time to ambulation and survival.

Results: The mean Tomita score was 6.3 \pm 2.4 . Thirty seven patients (74.0\%) required minimally invasive decompression in addition to MISt. The mean operating time was $2.3 \pm 0.5$ hours for MISt alone and 3.4 \pm 1.2 hours for MISt with decompression. Mean blood loss for MISt alone and MISt with decompression was $0.4 \pm 0.2 \mathrm{~L}$ and $1.7 \pm 0.9 \mathrm{~L}$, respectively. MISt provided a statistically significant reduction in visual analog scale pain score with mean preoperative score of $7.9 \pm 1.4$ that was significantly decreased to $2.5 \pm 1.2$ postoperatively ( $p=0.000$ ). For patients with neurological deficit, $70 \%$ displayed improvement of one Frankel grade and $5 \%$ had an improvement of 2 Frankel grades. No patient was bed-ridden postoperatively, with the average time to ambulation of $3.4 \pm 1.8$ days. The mean overall survival time was 11.3 months (range, 2-51 months). Those with a Tomita score $<8$ survived significantly longer than those a Tomita score $\geq 8$ with a mean survival of $14.1 \pm 12.5$ months and $6.8 \pm 4.9$ months, respectively $(p=0.019)$. There were no surgical complications, except one case of implant failure.

Conclusions: MISt is an acceptable treatment option for spinal metastatic patients, providing good relief of instability back pain with no major complications.
\end{abstract}

Keywords: Minimally invasive; Fluoroscopic guided; Percutaneous pedicle screw; Spine metastasis; Pathological fracture; Decompression

\section{Introduction}

The incidence of spinal metastases is increasing due to early detection and advances in the treatment of the primary tumour [1]. Spinal metastases can result in pathological fracture leading to instability back pain or even

\footnotetext{
Received Apr 30, 2015; Revised May 25, 2015; Accepted Jun 14, 2015

Corresponding author: Chee Kean Lee

Department of Orthopaedic Surgery, Faculty of Medicine, University of Malaya,

50603, Lembah Pantai, Kuala Lumpur, Malaysia

Fax: +603-79494642, Tel: +603-79492061, E-mail: kenetto@hotmail.com
} 
paralysis due to metastatic epidural spinal cord compression (MESCC). Instability back pain and/or neurological deficit can significantly affect quality of life [2]. Conventionally, patients with advanced disease are treated with nonoperative palliative care $[3,4]$. However, recent studies have demonstrated better quality of life, longer survival and improved neurological function in patients with MESCC who are treated with open decompressive surgery followed by radiotherapy, compared to radiotherapy alone $[5,6]$. Open surgical procedures are associated with significant risks and morbidities. Open surgery requires extensive muscle dissection with a higher risk of infection, increased blood loss, significant postoperative pain, longer hospitalization and time for functional recovery [7-9]. With the development of minimally invasive stabilization (MISt) using percutaneous pedicle screws, the morbidity associated with open surgery can be avoided. The case illustration in Fig. 1 is a good example illustrating the advantages using MISt in advanced spinal metastatic patients. The purpose of this paper is to report the outcome of 50 patients with spinal metastases who were treated with MISt using fluoroscopic-guided percutaneous pedicle screws with/without minimally invasive decompres- sion.

\section{Materials and Methods}

This was a prospective study carried out between January 2008 and December 2013. Eighty one consecutive spinal metastatic patients who presented with pathological fracture(s) associated with severe instability pain with/ without neurological deficit. The selection criterion for surgery included severe instability pain with presence of pathological fracture that did not improve with external orthosis support with/without neurological deficit secondary to MESCC. Instability pain was defined as mechanical pain in the presence of radiological evidence of pathological fracture(s) resulting in difficulty/limitation in turning the trunk in supine position, propping up in bed and/or sitting up from a lying position. The exclusion criteria were presence of neurological deficit without instability pain, poor candidates for general anaesthesia secondary to poor premorbid condition after assessment by an anaesthesiologist or extensive metastatic disease resulting in end organ failure (i.e., deranged liver functions, renal failure or brain with altered sensorium),
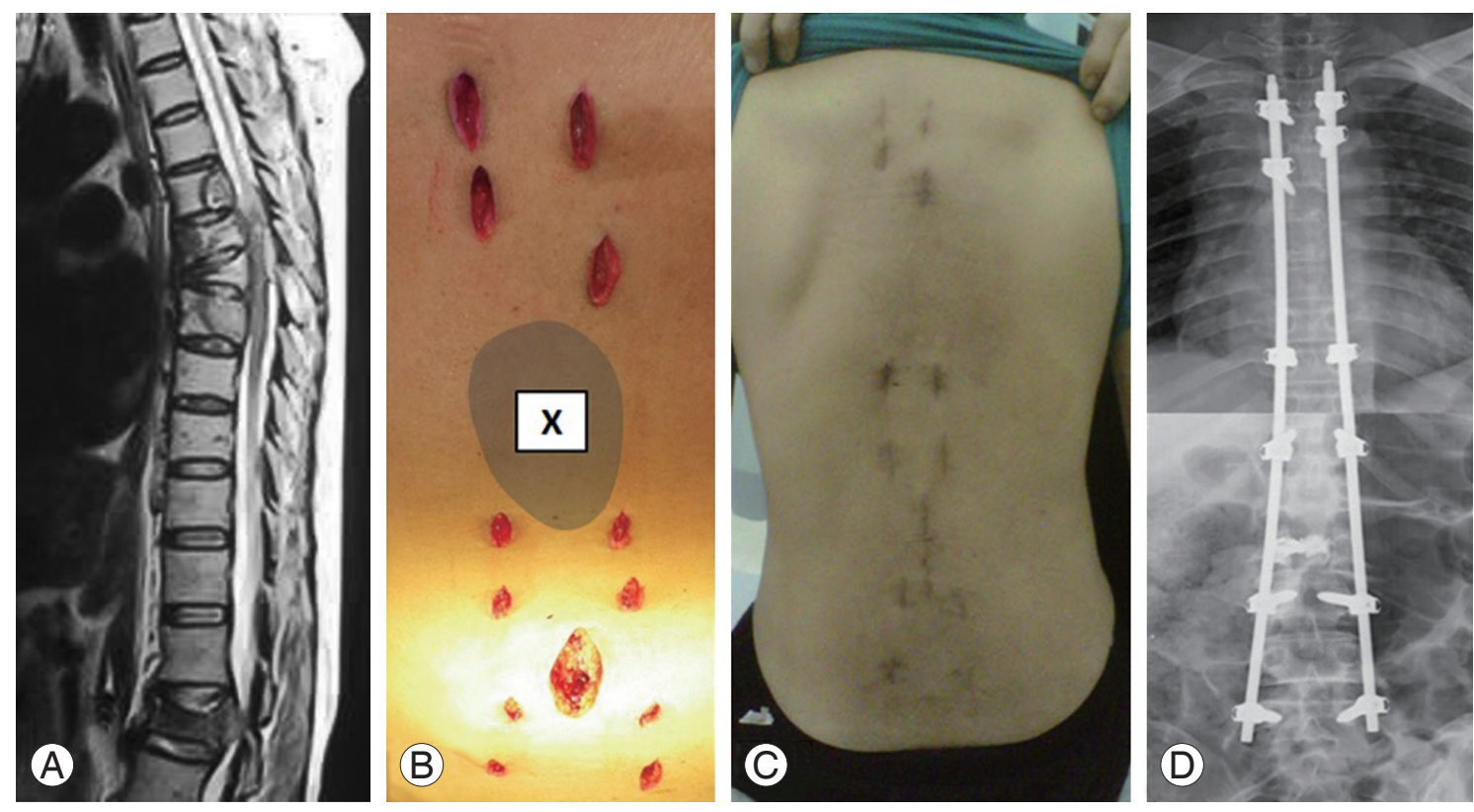

Fig. 1. Case 22: A 58-year-old woman with lung cancer presented with pathological fracture of $L 2$ with cauda equine syndrome. One month prior to the presentation, she had radiotherapy to the T6-T7 region for pathological fractures. (A) MRI showed pathological fractures of T6, T7, and L2 with spinal canal stenosis at L2 lead to cauda equine syndrome. (B) Intraoperative photo showed a multiple small stab wounds for percutaneous pedicle screws insertion. A minimally invasive direct decompression was performed at L2 region with cement augmentation for L2 fracture. The minimally invasive stabilization (MISt) construct spared the radiated zone (X). (C) Postoperative 2 weeks, the patient was able to sit up and mobilize with minimal pain. (D) Postoperative radiograph showed Long Construct MISt from T3-L5 spanning 15 spinal segments. 
Table 1. Demographic data and preoperative clinical status comparing patients with spinal metastasis who underwent minimally invasive stabilization (MISt) with decompression and MISt alone

\begin{tabular}{|c|c|c|c|}
\hline Variable & MISt with decompression ( $\mathrm{n}=37$ ) & MISt alone $(n=13)$ & Overall $(n=50)$ \\
\hline Age (yr) & $57.5 \pm 13.2$ & $52.8 \pm 10.1$ & $56.3 \pm 12.5$ \\
\hline \multicolumn{4}{|l|}{ Gender } \\
\hline Male & $18(48.6)$ & $7(53.8)$ & $25(50.0)$ \\
\hline Female & $19(51.4)$ & $6(46.2)$ & $25(50.0)$ \\
\hline \multicolumn{4}{|l|}{ Primary tumor } \\
\hline Breast & $14(37.8)$ & $3(23.1)$ & $17(34.0)$ \\
\hline Lung & $8(21.6)$ & $3(23.1)$ & $11(22.0)$ \\
\hline Prostate & $4(10.8)$ & $1(7.7)$ & $5(10.0)$ \\
\hline Renal & $4(10.8)$ & $1(7.7)$ & $5(10.0)$ \\
\hline Colorectal & $3(8.2)$ & $1(7.7)$ & $4(8.0)$ \\
\hline Others & $4(10.8)$ & $4(30.7)$ & $8(16.0)$ \\
\hline Tomita Score & $6.3 \pm .2 .4$ & $6.1 \pm 2.7$ & $6.3 \pm 2.4$ \\
\hline \multicolumn{4}{|l|}{ Level of fracture } \\
\hline 1 & $12(32.4)$ & $7(53.9)$ & $19(38.0)$ \\
\hline 2 & 18 (48.6) & $4(30.7)$ & $22(44.0)$ \\
\hline 3 or more & $7(19.0)$ & $2(15.4)$ & $9(18.0)$ \\
\hline Pain (VAS) & $7.8 \pm 1.5$ & $8.5 \pm 1.2$ & $7.9 \pm 1.4$ \\
\hline \multicolumn{4}{|l|}{ Neurology } \\
\hline \multicolumn{4}{|l|}{ Severity } \\
\hline Frankel A & $4(10.8)$ & $2(15.4)$ & $6(12.0)$ \\
\hline Frankel B & $1(2.7)$ & 0 & $1(2.0)$ \\
\hline Frankel C & 14 (37.8) & $2(15.4)$ & $16(32.0)$ \\
\hline Frankel D & $12(32.4)$ & $5(38.5)$ & $17(34.0)$ \\
\hline Frankel E & $6(16.3)$ & $4(30.7)$ & $10(20.0)$ \\
\hline \multicolumn{4}{|l|}{ Level } \\
\hline Thoracic & $16(51.6)$ & $5(55.6)$ & $21(52.5)$ \\
\hline Thoracolumbar & $12(38.7)$ & $4(44.4)$ & $16(40.0)$ \\
\hline Lumbar & $3(9.7)$ & 0 & $3(7.5)$ \\
\hline
\end{tabular}

Values are presented as mean \pm standard deviation or number (\%).

pathological fracture(s) involving the cervical or sacral spine, isolated single level lesion when excision surgery was possible, poor visualization of pedicles in fluoroscopic images, sclerotic metastatic lesions and patient refusal for surgery. After exclusion, 52 patients were recruited. They underwent MISt with/without minimally invasive decompression surgery. Two patients were lost to follow up. The remaining 50 patients comprised 25 males and 25 females, with a mean age of 56.3 years (range, 16-82 years). The primary tumors were breast (34.0\%, 17 cases), lung $(22.0 \%$, 11 cases), kidney (10.0\%, 5 cases), prostate $(10.0 \%, 5$ cases), colorectal ( $8.0 \%, 4$ cases) and others ( $16.0 \%, 8$ cases).
The demographic data and cases included are presented in Tables 1 and 2 .

\section{Preoperative protocol}

All patients underwent a magnetic resonance imaging (MRI) scan of the whole spine and a computed tomography (CT) scan of the thorac, abdomen and pelvis prior to surgical intervention. Clinically, they were assessed for pain using a visual analogue score (VAS), severity of neurology according to the Frankel classification [10] and Tomita score [3]. For those who also presented with neu- 
Table 2. Cases included for analysis in this study stratified to age, gender, primary tumor, VAS score, neurological status, Tomita score, and survivorship

\begin{tabular}{|c|c|c|c|c|c|c|c|c|c|}
\hline \multirow{2}{*}{\multicolumn{2}{|c|}{$\begin{array}{ll}\text { Case } & \text { Age } \\
\text { no. } & (y r)\end{array}$}} & \multirow{2}{*}{ Sex } & \multirow{2}{*}{ Primary } & \multirow{2}{*}{$\begin{array}{l}\text { Tomita } \\
\text { score }\end{array}$} & \multicolumn{2}{|c|}{ Neurology } & \multicolumn{2}{|c|}{ VAS } & \multirow{2}{*}{$\begin{array}{c}\text { Survived }^{\mathrm{c}} / \\
\text { deceased } \\
\text { (mo) }\end{array}$} \\
\hline & & & & & Preoperative & Postoperative $^{\text {a) }}$ & Preoperative & Postoperative $^{\mathrm{b})}$ & \\
\hline
\end{tabular}

\begin{tabular}{|c|c|c|c|c|c|c|c|c|c|}
\hline 1 & 49 & Female & Breast & 7 & $C$ & $E$ & 9 & 1 & 10 \\
\hline 2 & 54 & Female & Breast & 7 & C & $D$ & 9 & 3 & 3 \\
\hline 3 & 68 & Female & Breast & 3 & $D$ & $E$ & 7 & 3 & 36 \\
\hline 4 & 55 & Female & Breast & 7 & $E$ & $E$ & 10 & 4 & 11 \\
\hline 5 & 53 & Female & Breast & 3 & C & $D$ & 6 & 0 & 22 \\
\hline 6 & 75 & Female & Breast & 8 & $E$ & $E$ & 9 & 3 & 18 \\
\hline 7 & 54 & Female & Breast & 7 & $C$ & $D$ & 9 & 3 & 4 \\
\hline 8 & 45 & Female & Breast & 7 & C & D & 8 & 1 & 2 \\
\hline 9 & 54 & Female & Breast & 4 & $C$ & $D$ & 8 & 3 & 8 \\
\hline 10 & 62 & Female & Breast & 7 & $D$ & $E$ & 7 & 3 & 6 \\
\hline 11 & 64 & Female & Breast & 3 & $E$ & $E$ & 5 & 0 & 12 \\
\hline 12 & 36 & Female & Breast & 3 & $D$ & $E$ & 7 & 3 & $19^{\text {c) }}$ \\
\hline 13 & 55 & Female & Breast & 3 & $D$ & $E$ & 6 & 0 & $24^{\text {c) }}$ \\
\hline 14 & 44 & Female & Breast & 7 & C & $D$ & 5 & 2 & $16^{\mathrm{cl}}$ \\
\hline 15 & 55 & Female & Breast & 3 & $D$ & $E$ & 5 & 1 & $14^{\mathrm{c})}$ \\
\hline 16 & 61 & Female & Breast & 3 & $D$ & $D$ & 7 & 3 & 7 \\
\hline 17 & 50 & Female & Breast & 6 & $E$ & $E$ & 8 & 2 & $10^{\mathrm{c})}$ \\
\hline 18 & 62 & Female & Lung & 10 & $D$ & $D$ & 10 & 2 & 6 \\
\hline 19 & 76 & Male & Lung & 10 & $E$ & E & 8 & 3 & 6 \\
\hline 20 & 66 & Male & Lung & 10 & $E$ & $E$ & 10 & 4 & 2 \\
\hline 21 & 58 & Female & Lung & 8 & $D$ & $E$ & 9 & 3 & 8 \\
\hline 22 & 58 & Female & Lung & 10 & C & D & 7 & 2 & 7 \\
\hline 23 & 47 & Male & Lung & 5 & $D$ & $E$ & 6 & 2 & 10 \\
\hline 24 & 76 & Male & Lung & 8 & C & D & 9 & 5 & 2 \\
\hline 25 & 59 & Male & Lung & 10 & A & A & 8 & 3 & 2 \\
\hline 26 & 55 & Female & Lung & 10 & C & $D$ & 5 & 2 & 3 \\
\hline 27 & 55 & Female & Lung & 6 & $D$ & $E$ & 9 & 4 & $10^{\mathrm{c})}$ \\
\hline 28 & 82 & Male & Lung & 10 & A & C & 8 & 4 & $8^{c)}$ \\
\hline 29 & 46 & Male & Renal & 8 & C & $D$ & 10 & 5 & 6 \\
\hline 30 & 58 & Male & Renal & 4 & A & A & 10 & 2 & 2 \\
\hline 31 & 45 & Male & Renal & 4 & $D$ & $E$ & 9 & 3 & $51^{c)}$ \\
\hline 32 & 44 & Male & Renal & 8 & $E$ & $E$ & 7 & 2 & 4 \\
\hline 33 & 45 & Male & Renal & 4 & $C$ & $D$ & 7 & 2 & $10^{c)}$ \\
\hline 34 & 69 & Male & Prostate & 5 & C & D & 8 & 3 & 10 \\
\hline 35 & 48 & Male & Prostate & 4 & $D$ & $D$ & 9 & 3 & 28 \\
\hline 36 & 78 & Male & Prostate & 7 & C & $D$ & 8 & 1 & $39^{c)}$ \\
\hline 37 & 71 & Male & Prostate & 3 & $C$ & $\mathrm{D}$ & 7 & 2 & $36^{c)}$ \\
\hline 38 & 65 & Male & Prostate & 3 & C & D & 8 & 3 & 4 \\
\hline 39 & 71 & Male & Colorectal & 8 & $B$ & $C$ & 9 & 2 & 16 \\
\hline 40 & 56 & Male & Colorectal & 8 & A & A & 10 & 4 & 6 \\
\hline
\end{tabular}


Table 2. Continued

\begin{tabular}{|c|c|c|c|c|c|c|c|c|c|}
\hline \multirow{2}{*}{$\begin{array}{l}\text { Case } \\
\text { no. }\end{array}$} & \multirow{2}{*}{$\begin{array}{l}\text { Age } \\
\text { (yr) }\end{array}$} & \multirow{2}{*}{ Sex } & \multirow{2}{*}{ Primary } & \multirow{2}{*}{$\begin{array}{l}\text { Tomita } \\
\text { score }\end{array}$} & \multicolumn{2}{|c|}{ Neurology } & \multicolumn{2}{|c|}{ VAS } & \multirow{2}{*}{$\begin{array}{c}\text { Survived }^{c)} / \\
\text { deceased } \\
\text { (mo) }\end{array}$} \\
\hline & & & & & Preoperative & Postoperative $^{\text {a) }}$ & Preoperative & Postoperative $^{\text {b) }}$ & \\
\hline 41 & 57 & Male & Colorectal & 8 & A & A & 8 & 3 & 4 \\
\hline 42 & 58 & Female & Colorectal & 8 & $E$ & $E$ & 8 & 3 & 2 \\
\hline 43 & 34 & Female & Gastric & 9 & $E$ & $E$ & 10 & 3 & 12 \\
\hline 44 & 50 & Male & Liposarcoma & 8 & $E$ & $E$ & 9 & 3 & 14 \\
\hline 45 & 49 & Female & Melanoma & 6 & A & A & 7 & 3 & 5 \\
\hline 46 & 77 & Male & M Myeloma & 4 & $D$ & $E$ & 7 & 1 & 5 \\
\hline 47 & 46 & Male & M Myeloma & 4 & $D$ & $E$ & 9 & 2 & 3 \\
\hline 48 & 57 & Male & $\mathrm{NHL}$ & 4 & $D$ & $D$ & 6 & 0 & 18 \\
\hline 49 & 45 & Male & NPC & 3 & $D$ & $E$ & 8 & 4 & 2 \\
\hline 50 & 16 & Male & Osteosarcoma & 8 & D & D & 9 & 2 & 4 \\
\hline
\end{tabular}

VAS, visual analogue score; NHL, non Hodgkin lymphoma; NPC, nasopharyngeal carcinoma.

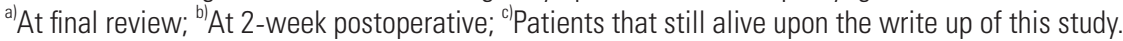

rological deficit, intravenous dexamethasone was administered on admission.

\section{Surgical technique}

Each patient was positioned prone on a radiolucent table allowing anteroposterior (AP) and lateral fluoroscopy. Percutaneous pedicle screws were inserted simultaneously on the left and right sides by two surgeons. This technique shortened the operative time and radiation exposure for both the patient and the operating staff.

A true AP view of the vertebra was obtained, in which the endplate was parallel and the pedicle was equidistance from the spinous process. A 2 -cm vertical skin incision was made just lateral to the pedicle edge for the thoracic screw insertion and 1-2 cm lateral to pedicle edge for the lumbar screw insertion. The thoracolumbar fascia was incised and the muscles were split parallel to its fibers. Two $11 \mathrm{G}$ trocars were engaged to the pedicle entry point simultaneously and advanced into the pedicle until the tip of trocars touched the medial pedicle wall on the true AP view. Once this was achieved, a lateral view image was obtained. On the lateral view, the tip of trocars needed to reach the posterior wall of the vertebral body to make sure that the trocars did not breach the medial pedicle wall. The trocars were then advanced to the middle of the vertebral body. Guide wires were then inserted and trocars were removed. Cannulated pedicle screws were in- serted following the direction of guide wires and the wires were removed once the screws were in position as guided by the lateral image. The same steps were repeated for the rest of the pre-determined instrumentation vertebrae.

When there was MESCC, a mini-open decompression was performed through a small midline incision of 3-4 $\mathrm{cm}$. Direct decompression was carried out depending on the location of neural compression When the anterior column was deficient, the anterior column was augmented either by percutaneous vertebroplasty or a cage. In cases where a cage was needed to reconstruct the anterior column, a larger midline incision $(6-8 \mathrm{~cm})$ was made. In such cases, a piecemeal vertebrectomy was performed after a wide laminectomy followed by removal of the ipsilateral pedicle as well as the rib and its articulation at the diseased level. This created sufficient space for cage insertion. The size of the cage that was chosen would depend on the space available. Patients with Frankel A neurology more than a week were not subjected to decompression surgery due to poor prognosis for neurological recovery. At the end of the procedure, the rods were contoured and inserted. Nuts were then inserted and final tightening of the whole construct was performed followed by closure of the deep fascia and skin.

\section{Postoperative protocol}

Operation wounds were inspected on Day 1 postopera- 
tively. After wound dressing, patients were referred for spinal rehabilitation and ambulation as soon as the postoperative pain was tolerable. All patients underwent radiotherapy approximately 2 weeks postoperatively. Those who received intravenous dexamethasone were gradually weaned off the drug.

Surgical data collected for analysis included operation time, blood loss, number of instrumented levels, number of screws, requirement of decompression, requirement of anterior augmentation, perioperative surgical complications and tumour recurrence at decompression site with worsening of neurology.

Outcome were assessed based on preoperative and postoperative pain VAS score, preoperative and postoperative neurological function according to Frankel grade, time to ambulation and survival period. Time to ambulation was defined by the period after the surgery until a patient was able to ambulate with a wheelchair, walker or unassisted. The postoperative pain score were assessed at 2 weeks and 3 months after surgery. The postoperative neurological assessments were performed immediately after surgery, and 2 weeks and 3 months postoperatively. Only the final assessment was recorded for analysis. The outcome of patients with advanced spine metastasis, defined as those with a Tomita score $\geq 8$ were further analyzed. This group of patients was routinely treated nonoperatively due to the poor prognostic nature of the disease [7]. Statistical analysis was carried out using independent $t$-test or Chi-squared test with statistical significance set at $p<0.05$.

\section{Results}

The mean Tomita score was $6.3 \pm 2.4$. The mean number of vertebra levels with pathological fractures was $1.8 \pm 0.8$. Of the 50 patients, 19 (38.0\%) involved single level pathological fracture, 22 (44.0\%) involved two levels and 9 (18.0\%) involved three levels or more. Most (80.0\%) presented with various grade of neurological deficits. Lesions at thoracic spine (52.5\%) was the main region causing the neurological deficit followed by thoracolumbar spine (40.0\%) (Table 1, Fig. 2).

Thirty seven patients (74.0\%) required decompression surgery in addition to MISt. The average operation time was 3.1 hours (range, 1-7 hours). When MISt without decompression was carried out, the mean operating time was 2.3 hours (range, 1-3 hours) while the mean operating time was 3.4 hours (range, 1.5-7 hours) when decompression was needed. The average blood loss was $1.4 \pm 1.0$ litres. Blood loss for MISt was $0.4 \pm 0.2 \mathrm{~L}$ and was $1.7 \pm 0.9 \mathrm{~L}$ for MISt plus decompression. The average number of instrumented vertebrae was 7.8 with the longest instrumentation spanning across 15 levels (Fig. 1, Table 3). The average number of screws inserted was 8 per patient. Twelve cases $(24.0 \%)$ displayed significant anterior column deficiency and required anterior column augmentation with

\section{Vertebral responsible for neurology level}

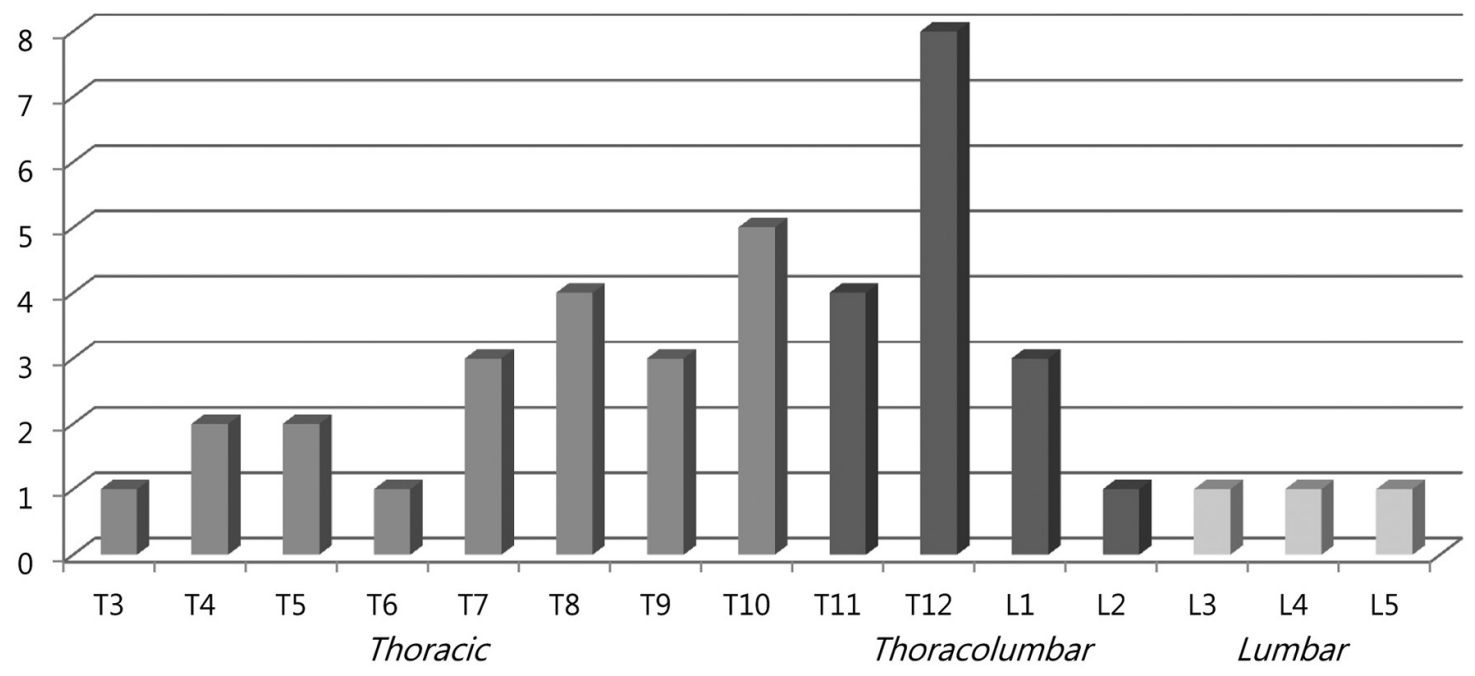

Fig. 2. Distribution of main vertebral level responsible for the neurological deficit in 40 patients. 
Table 3. Intraoperative parameters comparing patients with spinal metastasis who underwent minimally invasive stabilization (MISt) with decompression versus MISt alone

\begin{tabular}{|c|c|c|c|c|}
\hline Variable & Overall $(n=50)$ & $\begin{array}{l}\text { MISt with decompression } \\
\qquad(\mathrm{n}=37)\end{array}$ & MISt alone $(n=13)$ & $p$-value \\
\hline Operation time (hr) & 3. $1 \pm 1.2$ & $3.4 \pm 1.2$ & $2.3 \pm 0.5$ & $0.001^{\text {a) }}$ \\
\hline Blood loss (L) & $1.4 \pm 1.0$ & $1.7 \pm 0.9$ & $0.4 \pm 0.2$ & $0.000^{a)}$ \\
\hline No. instrumentation level & $7.8 \pm 2.6$ & $8.2 \pm 2.3$ & $6.8 \pm 3.1$ & 0.094 \\
\hline No. screws & $8.0 \pm 2.4$ & $8.4 \pm 2.4$ & $7.2 \pm 2.1$ & 0.120 \\
\hline Anterior augmentation & $12(24.0)$ & $8(21.6)$ & $4(30.8)$ & 0.506 \\
\hline Surgical complications & & & & - \\
\hline Worsening neurology & Nil & Nil & Nil & \\
\hline Infection & Nil & Nil & Nil & \\
\hline Wound dehiscence & Nil & Nil & Nil & \\
\hline Pulmonary complication & Nil & Nil & Nil & \\
\hline Screw-related injury & Nil & Nil & Nil & \\
\hline Implant failure & $1(2.0)$ & $1(2.7)$ & Nil & \\
\hline Early death (<30 day) & Nil & Nil & Nil & \\
\hline Tumour recurrence & Nil & Nil & Nil & - \\
\hline
\end{tabular}

Values are presented as mean \pm standard deviation or number (\%).

a) Significant difference.

either cement augmentation or cage (Table 3).

There was no postoperative infection, wound dehiscence, pulmonary complications, screw related injury or early death ( $<30$ days) noted in this study (Table 3$)$. However, there was one case of implant failure (case 31) diagnosed with renal cell carcinoma (Table 2). This case had a breakage of both rods at the thoracolumbar junction 27 months after the index surgery. The broken implants were revised using domino connectors. The patient has survived 51 months at the time of manuscript submission. None of patients had tumour recurrence at decompression site leading to recurrence or worsening of neurology. However, 2 patients had recurrence at a different site from the index level, which was decompressed. One patient required repeated decompression while the other received radiotherapy.

Overall, the mean preoperative, 2-week and 3-month postoperative pain score (VAS) was $7.9 \pm 1.4,2.5 \pm 1.2$ and $2.8 \pm 1.3$, respectively. There was significant pain reduction 2 weeks and 3 months after surgery compared to preoperatively (both $p<0.001$ ). Three months after surgery, the VAS for pain was no different from the 2-week postoperative value $(p=0.249)$. The 40 patients who presented with neurological deficit had an average of one Frankel grade recovery at final review; $70 \%$ had improvement of
1 grade and 5\% had an improvement of 2 grades. None of the patients had worsening of neurology after surgery (Table 3). Of the 10 patients who did not have neurological improvement, 50\% presented with complete paralysis (Frankel A) preoperatively (Fig. 3). None of the patients were bed-ridden after the surgery. The average time to ambulation was $3.4 \pm 1.8$ days.

The overall mean survival was 11.3 months (range, 2-51 months). During the final review, 39 patients had died, with an average survival of 8.5 months (range, 2-36 months), and 11 patients were still alive with an average survival of 21.5 months (range, 8-51 months). Based on the Kaplan-Meier survival analysis, the probability of survival was 0.54 at 6 month and 0.39 at 1 year (Fig. 4). When compared the patients with Tomita score $<8$ and those with Tomita score $\geq 8$, the pre- and postoperation pain score was higher for the latter group (Table 4). The Tomita $<8$ group had slightly shorter time to ambulation as compared to the Tomita $\geq 8$ group, but they were not significantly different. The group with the Tomita score $<8$ had a significant longer survival as compared to the group with the Tomita score $\geq 8$, with a mean survival of $14.1 \pm 12.5$ months and 6.8 \pm 4.9 months, respectively $(p=0.019)$ (Table 4). 


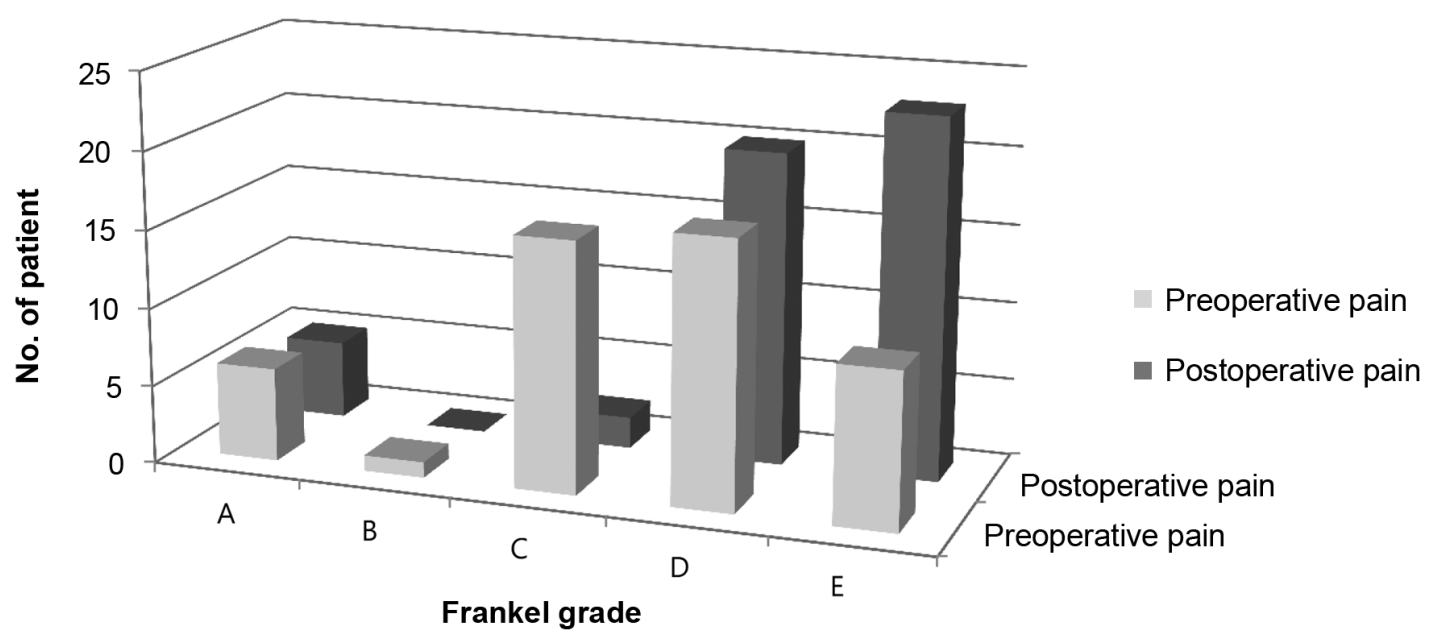

Fig. 3. Neurological outcome of patients with spinal metastasis who underwent minimally invasive stabilization with/without minimally invasive decompression, stratified to improvement according to Frankel grade.
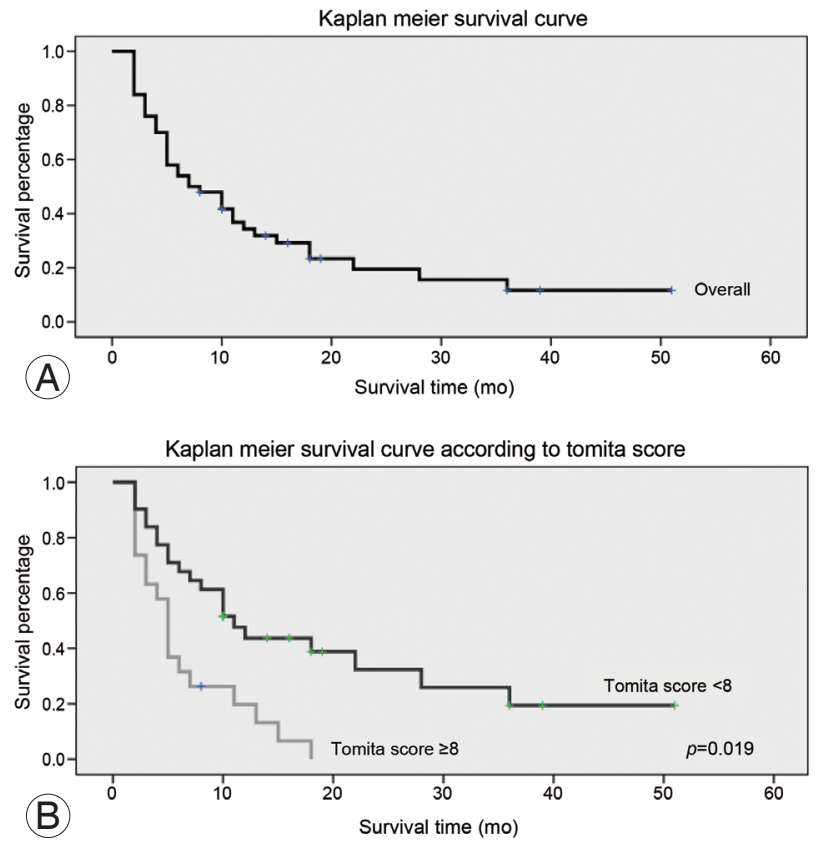

Fig. 4. (A, B) Kaplan-Meier survival analysis for patients with spinal metastasis who underwent minimally invasive stabilization with/without minimally invasive decompression.

\section{Discussion}

The incidence of skeletal metastases is as high as $70 \%$ in autopsy of cancer patients and spine is the most common site of bony metastases [11,12]. Most patients with spinal metastases present with instability back pain due to pathological fracture(s) $[13,14]$. Approximately $5-10 \%$ present with spinal cord compression resulting in neurological deficit $[15,16]$. Both instability pain and neurological deficit can significantly affect quality of life [2]. The patients are likely to be bed-bound because of intractable pain and neurological deficits. Immobilization in bed can lead to complications including orthostatic pneumonia, pressure sore, urinary tract infection, thromboembolism and joint contractures $[17,18]$.

The treatment for advanced spinal metastases (patients with Tomita score 28 ) often involves nonoperative palliative care due to their grave prognosis. Even patients with spinal metastases who present at an early stage with isolated spinal metastasis can rarely be treated with radical resection [3]. This is because any spread of the primary tumour to the spine is often considered the end stage of the disease. The decision for surgery is governed by three main factors: life expectancy, surgical indication and surgical risk. Life expectancy depends on the nature of the primary tumour, the extent of the metastases and the patients' general condition $[3,4]$. The indications for surgery are presence of spinal instability with/without neurological deficit $[19,20]$. However, the benefits of the surgery should outweigh the surgical risks when deciding for surgical intervention in this group of patients.

Life expectancy plays a major role when deciding surgery for spinal metastatic patients. Most surgeons recommend that surgery should be offered when life expectancy exceeds 3 months $[3,19,21]$. Tokuhashi et al. [4] suggested that surgery should be reserved for patients with expected survival of more than 6 months. These timing decisions are decided mainly because open procedures carry signifi- 
Table 4. Comparison of outcome between patients with spinal metastasis who underwent MISt with Tomita score $<8$ and $\geq 8$

\begin{tabular}{|c|c|c|c|}
\hline Variable & Tomita<8 (n=31) & Tomita $\geq 8$ (n=19) & $p$-value \\
\hline Age (yr) & $55.3 \pm 10.2$ & $57.8 \pm 15.9$ & 0.490 \\
\hline \multicolumn{4}{|l|}{ Sex } \\
\hline Male & $13(41.9)$ & $12(63.2)$ & 0.145 \\
\hline Female & $18(58.1)$ & $7(36.8)$ & 0.145 \\
\hline \multicolumn{4}{|l|}{ Pain (VAS) } \\
\hline Preoperative & $7.5 \pm 1.4$ & $8.6 \pm 1.3$ & $0.013^{\mathrm{cl}}$ \\
\hline Postoperative $^{a)}$ & $2.2 \pm 1.2$ & $3.1 \pm 1.0$ & $0.009^{c)}$ \\
\hline \multicolumn{4}{|l|}{ Neurology } \\
\hline No neurological deficit & $3(9.7)$ & $7(36.8)$ & $0.020^{c)}$ \\
\hline \multicolumn{4}{|l|}{ Neurological improvement } \\
\hline 0 grade & $5(16.1)$ & $5(26.3)$ & 0.382 \\
\hline 1 grade & $22(71.0)$ & $6(31.6)$ & $0.006^{c)}$ \\
\hline 2 grade & $1(3.2)$ & $1(5.3)$ & 0.721 \\
\hline Neurological worsening & 0 & 0 & NA \\
\hline Time to ambulation (day) & $3.4 \pm 1.3$ & $3.9 \pm 2.4$ & 0.375 \\
\hline Survival (mo) & $14.1 \pm 12.5$ & $6.8 \pm 4.9$ & $0.019^{c)}$ \\
\hline
\end{tabular}

Values are presented as mean \pm standard deviation or number (\%).

MISt, minimally invasive stabilization; VAS, visual analogue score; NA, not applicable.

${ }^{\text {a) }}$ At final review; ${ }^{\text {b) }}$ At 2-week postoperative; ${ }^{\text {c) }}$ Significant difference.

cant morbidity and mortality in patients with advanced spinal metastasis. However, in the absence of any surgical intervention, they suffer from intractable instability pain with an ever-ongoing poor quality of life. They will be more likely to bed-bound and to develop many complications as a result of immobilization in bed due to severe instability pain. In this study, there were 7 patients (14.0\%) that survived only 2 months after the index surgery. The main indication of surgery for these patients was to palliate and relieve their instability pain. MISt surgery had achieved significant reduction of pain in our study as evidenced from the pre- and postoperation pain score of VAS 7.9 and 2.5 , respectively $(p<0.001)$. Despite having 2 months of survival, these patients could sit up and had better ambulation after stabilization of their pathological fractures. The average duration to ambulate after surgery in this study was 3.4 days. This rapid recovery from surgery is attributed to the minimal muscle disruption in MISt $[8,22]$. Despite the short life expectancy in this group of patients, we believed that MISt can prevent them from being bed ridden and thus avoiding complications associated with immobilization. Even a short duration of survival with preservation of their ability to ambulate is very meaningful for these dying patients.

In this study, patients with Tomita score $\geq 8$ had mean survival of 6.8 months. This result compared favorably to a prior study, which reported a mean survival of 5.9 months for patients with a score $\geq 8$ [3]. The finding of longer survival in our patients that had undergone MISt with/without minimally decompression is consistent with prior results $[5,6]$. The longer survival could be attributed to the preservation of the ability to ambulate following stabilization of their pathological fracture through MISt and, therefore, reduction in complications of immobilization. Presently, we also noted that patients with Tomita score $\geq 8$ had significant more pain than those patients with Tomita score $<8$. Therefore, MISt can benefit these patients with Tomita score $\geq 8$ despite their poorer prognosis.

Open surgery in patients with spinal metastases is associated with higher complication rate $[21,23]$. The patients often display a poorer general condition as a consequence of their primary disease process as well as the adverse effects of chemotherapy and radiotherapy. The postoperative wound infection rate can be up to $12 \%$ for this group of patients $[5,24]$. If the patient has underwent ra- 
diotherapy prior to the surgery, the risk of dehiscence and wound infection is as high as 32\% [24]. Minimal invasive surgery reduces the infection rate because it reduces the physiological insult, decreases the recovery time and minimizes morbidity associated with more conventional open approach. O'Toole et al. concluded in their study that minimally invasive spinal surgery may reduce postoperative wound infections as much as 10-fold compared to open surgery [25]. In our study, there was no wound breakdown or infection in all 50 patients. In the case illustration (Fig. 1), we also demonstrated the versatility of MISt in avoiding an irradiated skin that is at higher risk of dehiscence. With the advancements of this surgical technique and instrumentation, MISt offers a new treatment option in patients with spinal metastases.

Patients with a low Tomita score $(<6)$ are expected to have 2 or more years of life expectancy [3]. The surgical strategy recommended by Tomita et al. [3] for this group of patient is excision. In our series, there were 20 patients with a Tomita score $<6$. The low score was due to their slow to moderate growth of primary tumours such as breast, prostate and kidney cancers, despite having multiple bony metastases. We excluded those patients with isolated or single level lesions when excision surgery was possible. Although they had a protracted prognosis, palliative surgery (i.e., MISt) was performed for them due to multiple lesions. All patients were given postoperative radiotherapy for local control.

The MISt technique allows the diseased spine to be effectively stabilized. However, this technique does not allow fusion of the diseased segment. The durability of the implants in patients with low Tomita score $(<6)$ is questionable. Of the 20 patients with low score, 5 survived longer than 24 months. One patient with a Tomita score 7 survived longer than 24 months (case 36). Only one implant failure happened in our series (case 31, Tomita score 4), giving rise to $2.0 \%$ failure rate (overall) and $16.7 \%(1 / 6)$ failure in those with protracted survival. In this case, the implant failure occurred at the mobile junctional segment of the spine (i.e., the thoracolumbar junction). The reason for the failure was attributed to the long survival (51 months) of the patient. Therefore, patients with potentially long survival i.e., Tomita score $<6$ will have to be informed that there is a risk of implants failure in the event they survive beyond 24 months. In such cases minimally invasive fusion in addition to MISt via minimally invasive facet joint fusion or minimally invasive percutaneous
BMP application could be safely performed [26,27].

In our series of patients who survived 3 months or less, three had Tomita score $<6$. None of them died because of surgery-related complications. The first patient (case 30) had renal cell carcinoma with Tomita score of 4 . He had Frankel A paralysis at presentation and his neurology did not improved despite decompression surgery. He passed away due to nosocomial pneumonia. The second patient (case 47) had multiple myeloma and a Tomita score of 4 . This patient died of renal failure. The last patient (case 49) was diagnosed with nasopharyngeal carcinoma. He had a Tomita score of 3 . His cause of death was respiratory failure secondary to uncontrolled locally advanced lymph nodes involvement.

There were a few limitations in this study. The primary tumours in these 50 patients with spinal metastasis were heterogenous. Different primary tumour would have different biological behavior and prognosis. The Spine Instability Neoplastic Score is the consensus from the Spine Oncology Study Group published in 2010 for assessment of instability in spinal metastasis [28]. This score was not used in our study because about half of the patients in this study were recruited from 2008-2010. There was also lack of assessment for quality of life in this study.

\section{Conclusions}

Percutaneous pedicle screw stabilization offers a treatment option for patients with spinal metastasis with spinal instability with or without neurological deficit secondary to MESCC. It provides significant relieve of pain with low risk of complications even in patients with advanced metastatic disease.

\section{Conflict of Interest}

No potential conflict of interest relevant to this article was reported.

\section{References}

1. Loblaw DA, Perry J, Chambers A, Laperriere NJ. Systematic review of the diagnosis and management of malignant extradural spinal cord compression: the Cancer Care Ontario Practice Guidelines Initiative's Neuro-Oncology Disease Site Group. J Clin Oncol 2005;23:2028-37. 
2. Wai EK, Finkelstein JA, Tangente RP, et al. Quality of life in surgical treatment of metastatic spine disease. Spine (Phila Pa 1976) 2003;28:508-12.

3. Tomita K, Kawahara N, Kobayashi T, Yoshida A, Murakami H, Akamaru T. Surgical strategy for spinal metastases. Spine (Phila Pa 1976) 2001;26:298-306.

4. Tokuhashi Y, Matsuzaki H, Toriyama S, Kawano H, Ohsaka S. Scoring system for the preoperative evaluation of metastatic spine tumor prognosis. Spine (Phila Pa 1976) 1990;15:1110-3.

5. Lee CH, Kwon JW, Lee J, et al. Direct decompressive surgery followed by radiotherapy versus radiotherapy alone for metastatic epidural spinal cord compression: a meta-analysis. Spine (Phila Pa 1976) 2014;39: E587-92.

6. Patchell RA, Tibbs PA, Regine WF, et al. Direct decompressive surgical resection in the treatment of spinal cord compression caused by metastatic cancer: a randomised trial. Lancet 2005;366:643-8.

7. Foley KT, Holly LT, Schwender JD. Minimally invasive lumbar fusion. Spine (Phila Pa 1976) 2003;28(15 Suppl):S26-35.

8. Kim DY, Lee SH, Chung SK, Lee HY. Comparison of multifidus muscle atrophy and trunk extension muscle strength: percutaneous versus open pedicle screw fixation. Spine (Phila Pa 1976) 2005;30:123-9.

9. Veeravagu A, Patil CG, Lad SP, Boakye M. Risk factors for postoperative spinal wound infections after spinal decompression and fusion surgeries. Spine (Phila Pa 1976) 2009;34:1869-72.

10. Frankel HL, Hancock DO, Hyslop G, et al. The value of postural reduction in the initial management of closed injuries of the spine with paraplegia and tetraplegia. I. Paraplegia 1969;7:179-92.

11. Coleman RE. Clinical features of metastatic bone disease and risk of skeletal morbidity. Clin Cancer Res 2006;12(20 Pt 2):6243s-6249s.

12. Hatrick NC, Lucas JD, Timothy AR, Smith MA. The surgical treatment of metastatic disease of the spine. Radiother Oncol 2000;56:335-9.

13. Helweg-Larsen S, Sorensen PS. Symptoms and signs in metastatic spinal cord compression: a study of progression from first symptom until diagnosis in 153 patients. Eur J Cancer 1994;30A:396-8.

14. Gilbert RW, Kim JH, Posner JB. Epidural spinal cord compression from metastatic tumor: diagnosis and treatment. Ann Neurol 1978;3:40-51.
15. Jacobs WB, Perrin RG. Evaluation and treatment of spinal metastases: an overview. Neurosurg Focus 2001;11:e10.

16. Schiff D, O’Neill BP, Suman VJ. Spinal epidural metastasis as the initial manifestation of malignancy: clinical features and diagnostic approach. Neurology 1997;49:452-6.

17. Dittmer DK, Teasell R. Complications of immobilization and bed rest. Part 1: Musculoskeletal and cardiovascular complications. Can Fam Physician 1993;39: 1428-32.

18. Teasell R, Dittmer DK. Complications of immobilization and bed rest. Part 2: Other complications. Can Fam Physician 1993;39:1440-2.

19. Bartels RH, van der Linden YM, van der Graaf WT. Spinal extradural metastasis: review of current treatment options. CA Cancer J Clin 2008;58:245-59.

20. Walker MP, Yaszemski MJ, Kim CW, Talac R, Currier BL. Metastatic disease of the spine: evaluation and treatment. Clin Orthop Relat Res 2003;(415 Suppl):S165-75.

21. Sciubba DM, Petteys RJ, Dekutoski MB, et al. Diagnosis and management of metastatic spine disease: a review. J Neurosurg Spine 2010;13:94-108.

22. Fan S, Hu Z, Zhao F, Zhao X, Huang Y, Fang X. Multifidus muscle changes and clinical effects of onelevel posterior lumbar interbody fusion: minimally invasive procedure versus conventional open approach. Eur Spine J 2010;19:316-24.

23. Pascal-Moussellard H, Broc G, Pointillart V, Simeon F, Vital JM, Senegas J. Complications of vertebral metastasis surgery. Eur Spine J 1998;7:438-44.

24. Ghogawala Z, Mansfield FL, Borges LF. Spinal radiation before surgical decompression adversely affects outcomes of surgery for symptomatic metastatic spinal cord compression. Spine (Phila Pa 1976) 2001;26: 818-24.

25. O’Toole JE, Eichholz KM, Fessler RG. Surgical site infection rates after minimally invasive spinal surgery. J Neurosurg Spine 2009;11:471-6.

26. Shim CS, Lee SH, Jung B, Sivasabaapathi P, Park SH, Shin SW. Fluoroscopically assisted percutaneous translaminar facet screw fixation following anterior lumbar interbody fusion: technical report. Spine (Phila Pa 1976) 2005;30:838-43.

27. Chan CY, Kwan MK, Saw LB, Hussin P. Feasibility of percutaneous posterolateral spinal fusion with 
Recombinant Bone Morphogenetic Protein-2 (rhBMP2): a comparison with standard methods using an animal model study. J Spinal Disord Tech 2013 Oct 30 [Epub]. http://dx.doi.org/ 10.1097/BSD. 0b013e3182aa6860.
28. Fisher CG, DiPaola CP, Ryken TC, et al. A novel classification system for spinal instability in neoplastic disease: an evidence-based approach and expert consensus from the Spine Oncology Study Group. Spine (Phila Pa 1976) 2010;35:E1221-9. 